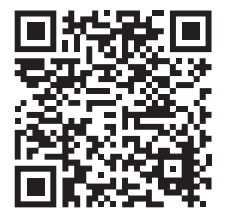

* Comisionado Nacional de Arbitraje Médico.

‡ Director de Investigación.

${ }^{\S}$ Director General de

Difusión e Investigación.

Comisión Nacional

de Arbitraje Médico

(CONAMED). México.

Correspondencia: $\mathrm{OMH}$, omunoz@conamed.gob. $\mathrm{mx}$

Conflicto de intereses:

No existe conflicto de intereses en la producción de este documento. Citar como: Muñoz HO Meneses-González F, Lezana FMÁ. La Comisión Nacional de Arbitraje Médico y la pandemia de COVID-19: actuar para la población y los profesionales de la salud. Rev CONAMED. 2021; 26(supl. 1): s6-s19. https:// dx.doi.org/10.35366/102576

Financiamiento: No se recibió financiamiento para la elaboración de este documento.

Recibido: 10/11/2021

Aceptado: 11/11/2021

\section{La Comisión Nacional de Arbitraje Médico y la pandemia de COVID-19: actuar para la población y los profesionales de la salud}

\author{
The National Medical Arbitration Commission and the COVID-19 \\ pandemic: taking action for the population and health professionals \\ Onofre Muñoz Hernández,* Fernando Meneses-González, ${ }^{\ddagger}$ \\ Miguel Ángel Lezana Fernández ${ }^{\S}$
}

\section{RESUMEN}

La pandemia de COVID-19 modificó, sustancialmente, la vida de los mexicanos en todos los ámbitos: individual, familiar, laboral y social. Este impacto se resintió en la vida de las instituciones que debieron adaptar y modificar las actividades a fin de dar continuidad con los planes y programas ya establecidos. Además de ello, instrumentar acciones para la protección de la salud de sus trabajadores. Este documento presenta cómo la Comisión Nacional de Arbitraje Médico (CONAMED) modificó sus actividades a fin de lograr continuar con su misión institucional.

Palabras clave: COVID-19, arbitraje, conciliación.

\section{ABSTRACT}

The COVID-19 pandemic substantially modified the lives of Mexicans in all areas: individual, family, work and social. This impact was felt in the life of the Institutions that had to adapt and modify the activities in order to give continuity with the plans and programs already established. In addition to this, implement actions to protect the health of their workers. This document presents how the National Medical Arbitration Commission (CONAMED) modified its activities in order to continue with its institutional mission.

Keywords: COVID-19, arbitration, conciliation. 


\section{INTRODUCCIÓN}

A partir de diciembre de 2019 se conoció en el mundo la presencia de un nuevo virus circulando desde China a diversos países del mundo. Este virus llamado desde ese momento como SARS-CoV-2, causante de la enfermedad COVID-19, generaba, inicialmente, un cuadro respiratorio grave con una letalidad elevada. El 30 de enero de 2020, la Organización Mundial de la Salud (OMS) declara el brote de COVID-19 como una emergencia en salud pública de interés internacional de acuerdo con el Reglamento Sanitario Internacional.'

Esta pandemia se declara presente en México con la atención del primer caso el 28 de febrero y el 11 de marzo de 2020 la OMS emite la declaratoria de pandemia por COVID-19. A partir de allí se implantaron una serie de medidas para lograr la protección de la población, prevenir el contagio y la atención de los casos. ${ }^{2}$

Para el caso de México y en específico de las instituciones gubernamentales, el 23y 24 de marzo de 2020 se emitieron dos decretos en los que se instruyó a las instituciones las medidas de protección de los trabajadores y de continuidad de las actividades. ${ }^{3,4}$

En este nuevo escenario laboral la Comisión Nacional de Arbitraje Médico (CONAMED) que tiene atención al público, tuvo que realizar algunos ajustes en su actividad, de manera tal que aquí se presenta cómo se realizaron las actividades a fin de continuar la misión institucional de resolución de controversias de los usuarios de los servicios de salud.

\section{Protección de los trabajadores}

A partir de los decretos secretariales publicados el 23 y 24 de marzo de 2020 en los que se establecieron las medidas a seguir con los trabajadores a fin de evitar el contagio, se enviaron a realizar «trabajo en casa» a las personas servidoras de 60 y más años de edad, así como a personas con discapacidad, mujeres embarazadas o en periodo de lactancia, y personas con enfermedades crónicas no transmisibles (diabetes; hipertensión arterial y pulmonar; insuficiencia hepática; obesidad mórbida; insuficiencia renal; lupus; cáncer; insuficiencia cardiaca; entre otras enfermedades, asociadas a un incremento en el riesgo de complicaciones); las actividades de los trabajadores que no aplicaban a esa categoría se desarrollaron con un nuevo esquema de «trabajo en casa» combinado con guardias presenciales para todas las áreas de la institución.

Con la finalidad de dar seguimiento al desarrollo de las actividades se instrumentó un reporte semanal de actividades para cada uno de los trabajadores que realizaban «trabajo en casa». El concentrado de esta información se enviaba, rutinariamente al Órgano Interno de Control en la CONAMED para conocimiento del mismo.

En 2020 la CONAMED contaba con 30 pasantes de servicio social, de los cuales 23 concluyeron el servicio social en julio y el resto formaba parte de los pasantes del segundo semestre del año. Los pasantes de servicio social con los que contaba la institución en ese periodo también fueron enviados a realizar las actividades de servicio social a su casa, manteniendo contacto con los tutores respectivos vía remota; se instrumentó un calendario de guardias con el objetivo de que ellos colaboraran con la implantación del filtro sanitario institucional.

Dado que la CONAMED es una institución pública gubernamental que ofrece mecanismos alternativos de solución de controversias entre usuarios y prestadores de servicios médicos y colabora con las autoridades de procuración e impartición de justicia, no se cerraron las puertas al público o a los prestadores de servicios de salud. El Instituto Nacional de Estadística y Geografía (INEGI) solicitó a la institución se le apoyara permitiéndole utilizar algunas de las oficinas por parte del personal encargado de invitar y capacitar a los ciudadanos que participarían en el censo 2020.

De allí que se tenía una importante movilidad por el público, los prestadores de servicio, el personal del INEGI, así como el personal de la institución que realizaba guardia laboral, por lo que, a fin de evitar el potencial contagio de «fuera-dentro», se instaló un filtro sanitario con un sistema de vigilancia sindrómico.

\section{Filtro sanitario}

Este filtro se instaló en la zona de ingreso a las instalaciones y el funcionamiento estuvo a cargo 


\section{SALUD CONAMED}

Tamizaje de vigilancia sindrómica de la infección respiratoria aguda

FECHA:

\begin{tabular}{|l|l|}
\hline DELEGACIÓN/MPIO: & CODIGO POSTAL \\
\hline
\end{tabular}

\begin{tabular}{l|l}
\hline TEMPERATURA RECISTRADA: & gradosC \\
\cline { 2 - 2 }
\end{tabular}

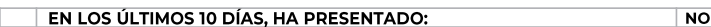

I. TOS

2. FIEBRE MAYORA LOS $38^{\circ} \mathrm{C}$

3. CEFALEA (en menores de cinco años de edad, la irritabilidad puede sustituir a la

cefalea)?

4. DISNEA (DIFICULTAD PARA RESPIRAR)

5. ARTRALGIAS

6. MIALGIAS

7. ODINOFAGIA/ARDORFARÍNGEO

8. RINORREA

9. CONJUNTIVITIS

10. DOLORTORÁCICO

11. PERDida DEL OLFATO (ANOSMIA)

12. PERDIDA DEL GUSTO (NO LE SABE LA COMIDA O LAS COSAS) (DISGEUSIA)

13. EN LOS ÚLTIMOS 14 DÍAS, ¿HA TENIDO CONTACTO CON ALGUIEN CON

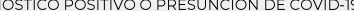

14. USTED HA SIDO DIAGNOSTICADO COMO POSITIVO A COVID-19?

En caso de que se registre una temperatura mayor a $38^{\circ} \mathrm{C}$, realizar las siguientes acciones:

Explicarle a la persona que no puede ingresar a las instalaciones de la CONAMED

Recomendarle que acuda a su médico y a su domicilio para realizar el distanciamiento social

Definiciones Operacionales.

CASO SOSPECHOSO

位 siguientes signos y síntomas: tos, fiebre, disnea (dato de gravedad) o cefalea (en menores de cinco

1. Mialgias,

2. Artralgias;

Odinofagia/ardor faríngeo

4. Escalofrios
5. Dolor torácico

12. ¿CUMPLE CON LA DEFINICIÓN OPERACIONAL DE CASO SOSPECHOSO?

Perdida del olfato

Conjuntivitis;

Figura 1: Formato de vigilancia epidemiológica sindrómica utilizado en el filtro sanitario instalado en la CONAMED, México 2020-2021. de los pasantes de servicio social de enfermería y medicina que realizaban la guardia asignada. La actividad consistió en instrumentar un ejercicio de vigilancia epidemiológica para aplicar a cada usuario que ingresaba a la institución un cuestionario de vigilancia sindrómica (Figura 7), toma de temperatura y la aplicación de gel en manos, estas medidas incluyeron al personal de la institución.

A la salida de la institución, a los usuarios externos se les proporcionaban folletos informativos relacionados con las medidas de prevención para reducir el riesgo de infección por COVID-19.

Durante el periodo de marzo a noviembre de 2020 se llenaron 2,126 cuestionarios y solamente se detectó, en el mes de mayo, un usuario compatible con datos de infección por COVID-19 (tasa de incidencia del periodo: 4.7 casos por 10,000 usuarios), misma que fue enviada a los servicios de salud. La mayor frecuencia de usuarios se registró en los meses de marzo y agosto (21.0 y 15.5\%, respectivamente).

\section{Comunicación a distancia}

El seguimiento de las actividades del personal, así como de la toma de decisiones de los directivos, tuvo que adaptarse a la nueva modalidad de trabajo en casa, por lo que se implantaron inicialmente varias plataformas de comunicación a distancia que al inicio de la pandemia estuvieron en modalidad gratuita, de allí que las reuniones internasy de

Tabla 1: Atenciones proporcionadas por la Comisión Nacional de Arbitraje Médico, abril-diciembre 2020.

\begin{tabular}{|c|c|c|c|c|c|c|c|c|c|c|}
\hline & $\begin{array}{c}\text { Orienta- } \\
\text { ciones }\end{array}$ & $\%$ & Asesorías & $\%$ & $\begin{array}{l}\text { Gestiones } \\
\text { inmediatas }\end{array}$ & $\%$ & Quejas & $\%$ & $\begin{array}{l}\text { Dictá- } \\
\text { menes }\end{array}$ & $\%$ \\
\hline Abril & 71 & 2.0 & 109 & 4.9 & 156 & 15.2 & 4 & 1.2 & 1 & 1.5 \\
\hline Mayo & 57 & 1.6 & 133 & 6.0 & 109 & 10.6 & 0 & 0.0 & 0 & 0.0 \\
\hline Junio & 68 & 1.9 & 157 & 7.1 & 111 & 10.8 & 131 & 39.8 & 19 & 27.9 \\
\hline Julio & 130 & 3.7 & 164 & 7.4 & 172 & 16.8 & 23 & 7.0 & 10 & 14.7 \\
\hline Agosto & 283 & 8.1 & 127 & 5.7 & 135 & 13.2 & 8 & 2.4 & 6 & 8.8 \\
\hline Septiembre & 71 & 2.0 & 128 & 5.8 & 115 & 11.2 & 28 & 8.5 & 3 & 4.4 \\
\hline Octubre & 177 & 5.1 & 780 & 35.3 & 35 & 3.4 & 83 & 25.2 & 12 & 17.6 \\
\hline Noviembre & 506 & 14.4 & 410 & 18.6 & 73 & 7.1 & 26 & 7.9 & 8 & 11.8 \\
\hline Diciembre & 2,140 & 61.1 & 201 & 9.1 & 118 & 11.5 & 26 & 7.9 & 9 & 13.2 \\
\hline Total & 3,503 & 49.1 & 2,209 & 31.0 & 1,024 & 14.4 & 329 & 4.6 & 68 & 1.0 \\
\hline
\end{tabular}


Tabla 2: Quejas concluidas por modalidad de conclusión y mes. CONAMED, México. Abril-diciembre 2020.

\begin{tabular}{|c|c|c|c|c|c|c|c|c|c|c|c|c|}
\hline & Modalidad & Abril & Mayo & Junio & Julio & Agosto & $\begin{array}{l}\text { Sep- } \\
\text { tiembre }\end{array}$ & $\begin{array}{l}\text { Octu- } \\
\text { bre }\end{array}$ & $\begin{array}{l}\text { No- } \\
\text { viem- } \\
\text { bre }\end{array}$ & $\begin{array}{l}\text { Diciem- } \\
\text { bre }\end{array}$ & Total & $\%$ \\
\hline \multirow[t]{3}{*}{$\begin{array}{l}\text { Conciliación } \\
\text { (N = 115; 35.0\%) }\end{array}$} & $\begin{array}{l}\text { Por aclaración } \\
\text { aceptada }\end{array}$ & 1 & 0 & 16 & 0 & 3 & 7 & 12 & 3 & 1 & 43 & 37.4 \\
\hline & $\begin{array}{l}\text { Por } \\
\text { desistimiento } \\
\text { de la acción }\end{array}$ & 0 & 0 & 0 & 0 & 0 & 0 & 1 & 0 & 0 & 1 & 0.9 \\
\hline & Por transacción & 0 & 0 & 25 & 0 & 3 & 8 & 23 & 7 & 5 & 71 & 61.7 \\
\hline \multirow[t]{4}{*}{$\begin{array}{l}\text { No conciliación } \\
(\mathrm{N}=202 ; 61.4 \%)\end{array}$} & $\begin{array}{l}\text { Por } \\
\text { desistimiento } \\
\text { de la instancia } \\
\text { u otros }\end{array}$ & 0 & 0 & 0 & 0 & 1 & 0 & 0 & 0 & 0 & 1 & 0.6 \\
\hline & $\begin{array}{l}\text { Por falta de } \\
\text { voluntad } \\
\text { conciliatoria }\end{array}$ & 2 & 0 & 74 & 3 & 0 & 10 & 42 & 9 & 16 & 156 & 98.1 \\
\hline & $\begin{array}{l}\text { Por falta de } \\
\text { interés procesal }\end{array}$ & 1 & 0 & 16 & 13 & 0 & 1 & 4 & 4 & 3 & $42^{*}$ & 0 \\
\hline & $\begin{array}{l}\text { Por } \\
\text { fallecimiento } \\
\text { del quejoso }\end{array}$ & 0 & 0 & 0 & 3 & 0 & 0 & 0 & 0 & 0 & 3 & 1.9 \\
\hline \multirow{4}{*}{$\begin{array}{l}\text { Por laudo } \\
(\mathrm{N}=12 ; 3.6 \%)\end{array}$} & Absolutorio & 0 & 0 & 0 & 3 & 1 & 2 & 1 & 1 & 0 & 8 & 66.7 \\
\hline & Condenatorio & 0 & 0 & 0 & 1 & 0 & 0 & 0 & 2 & 1 & 4 & 33.3 \\
\hline & Total & 4 & 0 & 131 & 23 & 8 & 28 & 83 & 26 & 26 & 329 & \\
\hline & $\%$ & 1.2 & 0.0 & 39.8 & 7.0 & 2.4 & 8.5 & 25.2 & 7.9 & 7.9 & & \\
\hline
\end{tabular}

*NO se incluyen en la estimación de proporciones.

seguimiento del personal se realizaron utilizando esas plataformas (Zoom, Cisco Webex, Telmex, entre otras). El uso de estas plataformas permitió mantener el contacto con el personal para el reporte de las actividades laborales semanalmente.

\section{La mudanza}

En octubre de 2020 la CONAMED fue informada que tendría que dejar el edificio sede que durante casi 25 años alojó a la institución y mudarse a un edificio que concentra una buena parte de las unidades de la Secretaría de Salud.

Esta mudanza obligó a los directivos y trabajadores de la CONAMED a desarrollar un ejercicio de empaque de enseres en un tiempo limitado y la posibilidad de que alguno de los trabajadores se infectara de COVID-19. La mudanza no requería llevarse mobiliario y sí, exclusivamente, la documentación necesaria para continuar con las actividades en la nueva sede. El empaque se organizó en los días que el personal tenía su guardia y, afortunadamente, después del ejercicio de mudanza no se detectó a algún trabajador contagiado por COVID-19.

\section{Atención al público y profesionales de la salud}

En ese esquema de desarrollo de actividades, las áreas de conciliación y de arbitraje continuaron con su actividad, hay que comentar que en el año 
2020 ingresaron a la CONAMED 11,382 asuntos, de los cuales la mayor proporción fueron orientaciones $(5,824 ; 51.2 \%)$ y asesorías $(3,266 ; 28.7 \%)$, así como quejas (804; 7.1\%); para el año 2021 (hasta el mes de septiembre), se mantuvo el mismo patrón (10,911 asuntos), de los cuales fueron 6,475 orientaciones (59.3\%), 2,909 asesorías (26.7\%) y 607 quejas (5.7\%). Del primero de abril al 31 de diciembre de 2020 se atendieron 7,133 asuntos, de los cuales 3,503 (49.1\%) fueron orientaciones; 2,209 (31.0\%) asesorías; 1,024 (14.4\%) gestiones inmediatas y se concluyeron 329 quejas (4.6\%), así como 68 dictámenes médicos institucionales (1.0\%).

En relación con las orientaciones, la mayor proporción se atendieron en los meses de diciembre y noviembre (61.1 y 14.4\%, respectivamente); en el caso de las asesorías, los meses de octubre y noviembre reportaron la mayor proporción de este servicio (35.3 y 18.6\%, respectivamente). En relación con las gestiones inmediatas, julio y abril fueron los meses con mayor actividad (16.8 y 15.2\%, respectivamente); por otro lado, los meses con la mayor proporción de quejas concluidas fueron junio y octubre (39.8 y 25.2\%, respectivamente); finalmente, en relación con los dictámenes emitidos, también los meses de junio y octubre reportaron la mayor proporción (27.9 y 17.6\%, respectivamente) (Tab/a 7).

De 329 quejas que se concluyeron del mes de abril a diciembre de 2020, 35\% (115) fueron concluidas con una conciliación y de éstas 61.7\% (71) se resolvieron con una transacción. De las quejas que no se conciliaron, $77.2 \%$ quedaron en esa categoría por falta de voluntad conciliatoria de alguna de las partes y de los laudos emitidos 66.7\% fueron absolutorios. En la Tabla 2 se muestra también la distribución de estas quejas concluidas por mes y resaltan los meses de junio y octubre en los que se tuvo una mayor productividad por las áreas responsables de estas actividades.

En el periodo del 30 de marzo de 2020 al 30 de septiembre de 2021 la CONAMED recibió 377 inconformidades por la atención de pacientes COVID-19, 285 (75.6\%) durante 2020 y 92 (24.4\%) durante 2021. De ese total, 245 (65.0\%) se atendieron como asesoría, 117 (31\%) como gestiones inmediatas y 15 (4.0\%) se ingresaron como quejas médicas.

De las asesorías proporcionadas, 86 (35.1\%) se desarrollaron como asesorías médicas relacionadas con la atención médica de prestadores públicos, de unidades médicas que brindaban atención para pacientes COVID-19, para solicitar la realización y resultados de pruebas para detección de COVID-19, realización de trámites en instituciones, o bien resolver dudas sobre la pandemia. Noventa (36.7\%) fueron asesorías relacionadas con el procedimiento para ingresar una queja en la CONAMED; finalmente, 69 (28.2\%) asesorías fueron de carácter jurídico que entre los temas que se trataron fueron: cobros excesivos de la atención, temas laborales relacionados con el paciente COVID-19; solicitud de copias del expediente clínico del paciente; orientación sobre la entrega de cadáveres, o bien por la negación de entrega de paciente o cadáver por falta de pago; el llenado y trámites relacionados con el certificado de defunción; la denuncia de prestadores no certificados o con prácticas inadecuadas, el maltrato por servidores públicos o por falta de medidas sanitarias en el lugar de trabajo.

En relación con las gestiones inmediatas, $62.4 \%$ (73) de los usuarios solicitaban una explicación en relación con la atención médica que estaban proporcionándole al paciente COVID-19, 24.8\% (29) requerían información sobre la atención médica y 12.8\% (15) gestionaban una atención médica urgente; realización de estudios complementarios; que se proporcionaran medicamentos, así como la revaloración del paciente o el traslado del mismo.

De las 117 gestiones inmediatas atendidas, en 108 (92.3\%) se facilitó su resolución por el personal de la CONAMED y en las nueve (7.7\%) restantes no se logró.

De las 15 quejas ingresadas, 12 de ellas (80.0\%) solicitaban indemnización por la atención recibida y las tres (20.0\%) restantes el reembolso de lo que habían erogado en la atención del paciente COVID-19. De esas quejas, dos (13.3\%) de ellas fueron conciliadas, en tres (20.0\%) no se logró la conciliación, dos (13.3\%) pasaron al arbitraje, cuatro (26.7\%) aún se encuentran en proceso y sólo cuatro (26.7\%) no se concluyeron por falta de interés procesal.

\section{Capacitación}

Las actividades de capacitación presenciales fueron suspendidas, ello incluyó, además de los 
cursos programados, el «Curso de prevención del conflicto derivado del acto médico» que estaba previsto para ofrecerse de manera presencial en ocho ocasiones durante el año, uno por mes. La importancia de este curso radica no sólo en la temática que aborda, sino que tiene reconocimiento como curso de Educación Continua por la Facultad de Medicina de la Universidad Nacional Autónoma de México.

Ante la cancelación del curso presencial se decidió reestructurarlo, organizarlo y sacarlo en una versión en línea con el mismo reconocimiento universitario. Gracias al esfuerzo de los profesores invitados y al equipo de trabajo de la institución, el curso estuvo listo en septiembre y se puso a disposición en la plataforma Moodle desarrollada por la institución, logrando ofrecer tres cursos en línea autogestivo, en los meses de octubre, noviembre y diciembre con una audiencia total de 72 estudiantes inscritos.

Por otro lado, el compromiso institucional con los pasantes de servicio social para el desarrollo de sus actividades se fortaleció con la comunicación en línea con sus tutores y se instrumentó el curso en línea «Inducción a la investigación para pasantes de servicio social» con 50 horas de duración. De la misma forma se organizó un curso en línea sobre «Aspectos normativos de la práctica médica» de 15 horas de duración para estudiantes de pregrado de medicina de la Universidad Panamericana en el que participaron 47 asistentes.

\section{Conferencias}

Durante 2020 se programaron 130 conferencias, todas ellas presenciales, pero con el confinamiento se suspendieron las actividades presenciales. Sólo se lograron impartir 43 conferencias de las que 19 fueron de manera presencial (antes del confinamiento) y durante el confinamiento se impartieron 24 por videoconferencia. La bondad de la comunicación a través de plataformas permitió que del total de asistentes en las conferencias impartidas (9,719 asistentes) se tuviera una participación de 2,868 asistentes en las 19 conferencias presenciales, mientras que en las 24 videoconferencias se contó con 6,851 asistentes (29.5 y $70.5 \%$, respectivamente).

\section{Difusión de información a profesionales de la salud y público en general}

La COVID-19 como una enfermedad nueva que estaba afectando a grupos poblacionales de manera diferenciada, impulsó a la comunidad científica a investigar desde diferentes perspectivas el impacto del virus en la salud poblacional. El avance del trabajo científico relacionado con el virus fue muy intenso, tan es así que la mayoría de las revistas científicas abrieron sus espacios para recibir publicaciones relacionadas con COVID-19 y los artículos estuvieron, en la mayoría de ellas, disponibles de manera gratuita. La información que se publicaba día a día superaba a cualquiera que quisiera leerla, pero era importante tener la información básica que sirviera a los profesionales de la salud para la atención de los casos y, de forma también importante, en la prevención del contagio poblacional.

La CONAMED se dio a la tarea de producir infografías relacionadas con acciones de protección contra COVID-19, tanto para profesionales de la salud, especialmente a los médicos de primer contacto y a odontólogos, así como al público en general y a los trabajadores de la institución. En el periodo de confinamiento de 2020 se produjeron ocho materiales que se colocaron en la página web de la CONAMED y se encuentran disponibles de manera gratuita (www.gob.mx/conamed), de éstas se realizaron 16,910 descargas. Asimismo, fueron distribuidas por el listado de correos (mailing list) con el que se cuenta y donde se tienen registrados a 39,383 usuarios; también se distribuyeron en las redes sociales de la institución, específicamente Facebook que cuenta con 49,654 seguidores, como ejemplo se presentan tres infografías (Figuras 2 a 4).

\section{Distribución de carteles impresos}

Durante los meses de junio y julio de 2020, la CONAMED distribuyó en las comisiones estatales de Arbitraje Médico y en los Servicios Estatales de Salud de aquellas entidades que no cuentan con una comisión estatal, 10 carteles relacionados al quehacer de los profesionales de la salud, distribuyéndose en total 47,657 ejemplares. Tales 


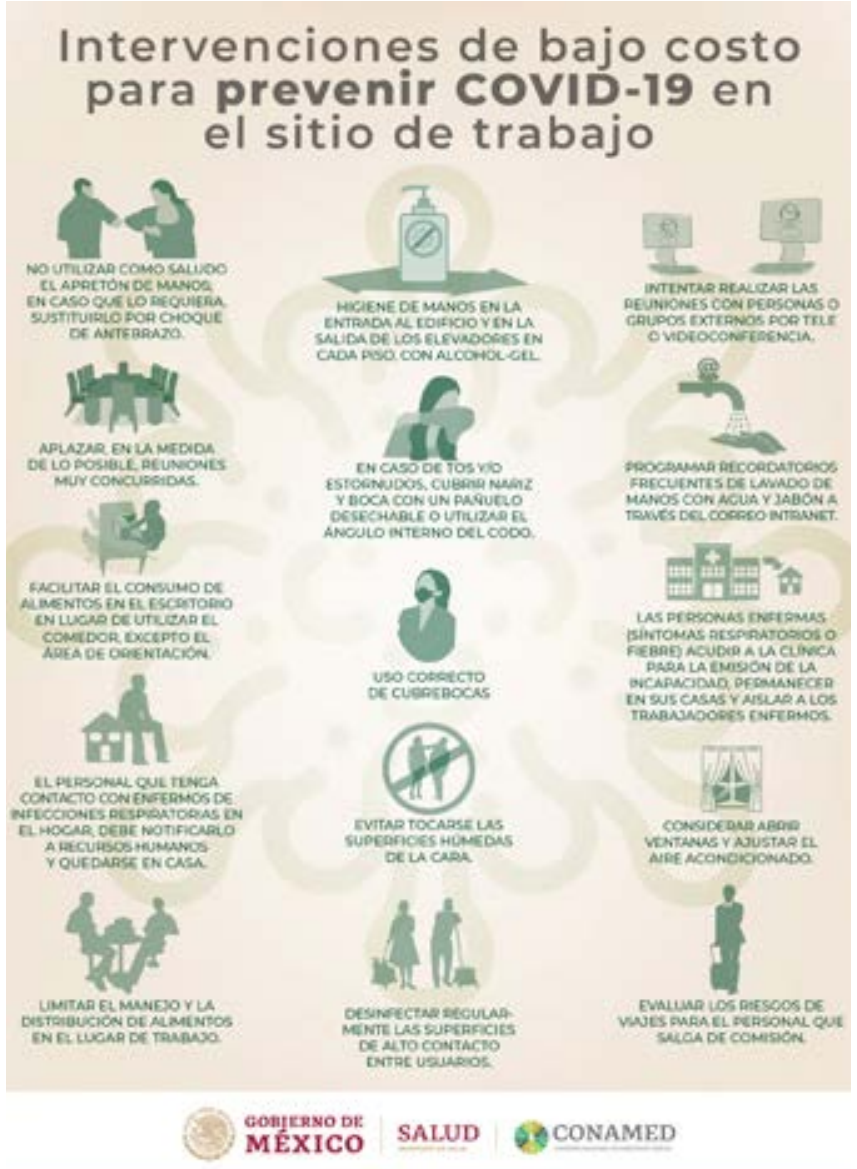

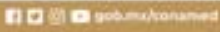

Figura 2: Infografía dirigida al personal de salud y público en general. CONAMED. México, 2020.

carteles incluyeron diversos temas, entre otros, «10 Derechos Generales de las y los Trabajadores de la Salud» y «Elementos básicos de una receta médica» (Figura 5).

\section{Revista CONAMED}

La CONAMED cuenta con la Revista CONAMED, que es el órgano de comunicación científica oficial de la misma; a partir de 2018 dejó de distribuirse en formato impreso y pasó a un formato electrónico. Durante 2020 se siguió editando y publicando en sus cuatro números ordinarios y un suplemento. Este último (volumen 25, suplemento 1, 2020) fue un número especial titulado COVID-19 y el consultorio médico. En la siguiente liga se puede revisar el número completo: https://
WWW.medigraphic.com/pdfs/COMPLETOS/ conamed/2020/cons201.pdf

En 2020, la Revista CONAMED registró 361,699 visitas con un promedio diario de 994 visitas. Por otro lado, el total de consultas con descarga de la versión completa de algún artículo en pdf fue de 412,871 con un promedio diario de 1,131.

\section{Webinar «El COVID-19 y el consultorio médico»}

A fin de contribuir con la difusión de información técnica relacionada con la pandemia de COVID-19, el cuadro clínico, el diagnóstico, las mejores opciones de tratamiento y el manejo de aquellos pacientes con otros padecimientos,

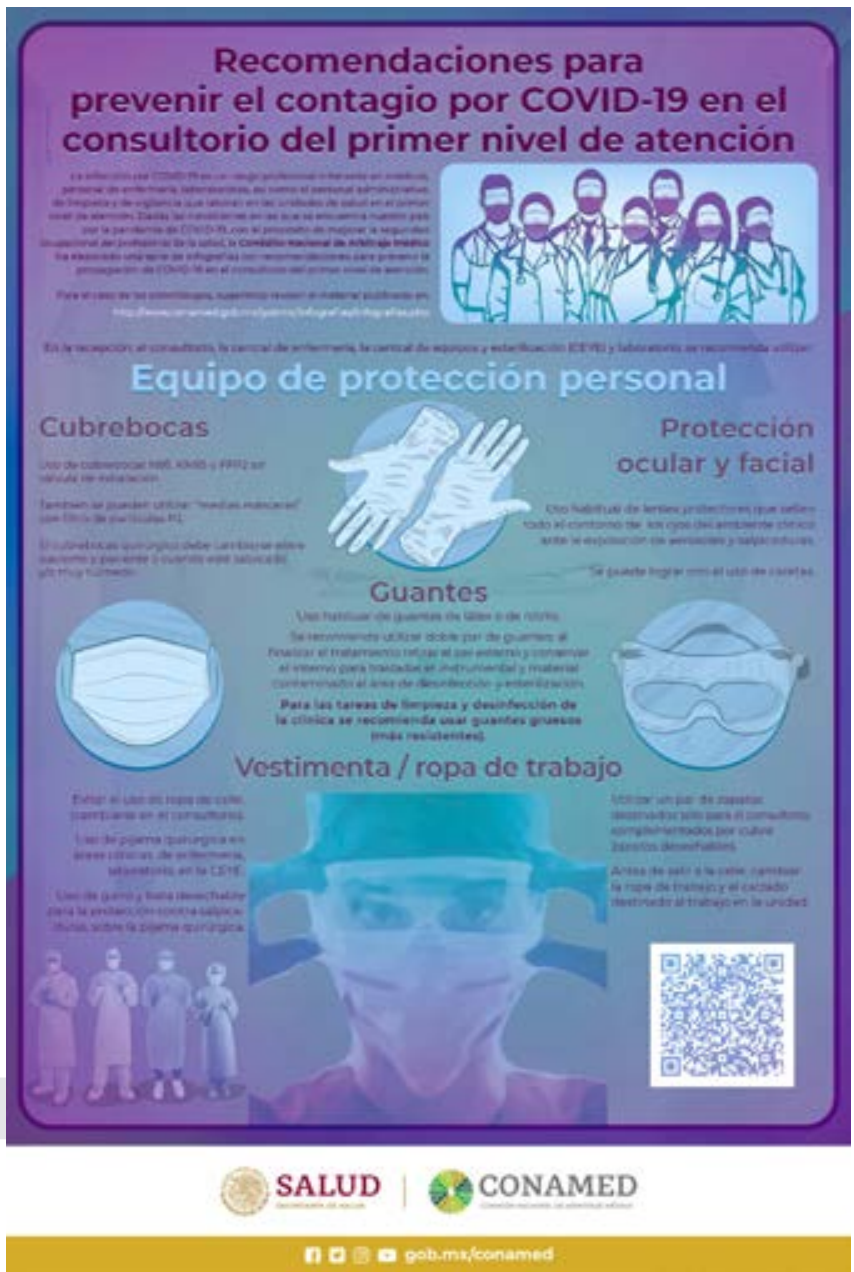

Figura 3: Infografía dirigida al personal de salud en el consultorio de primer nivel de atención. CONAMED. México, 2020. 


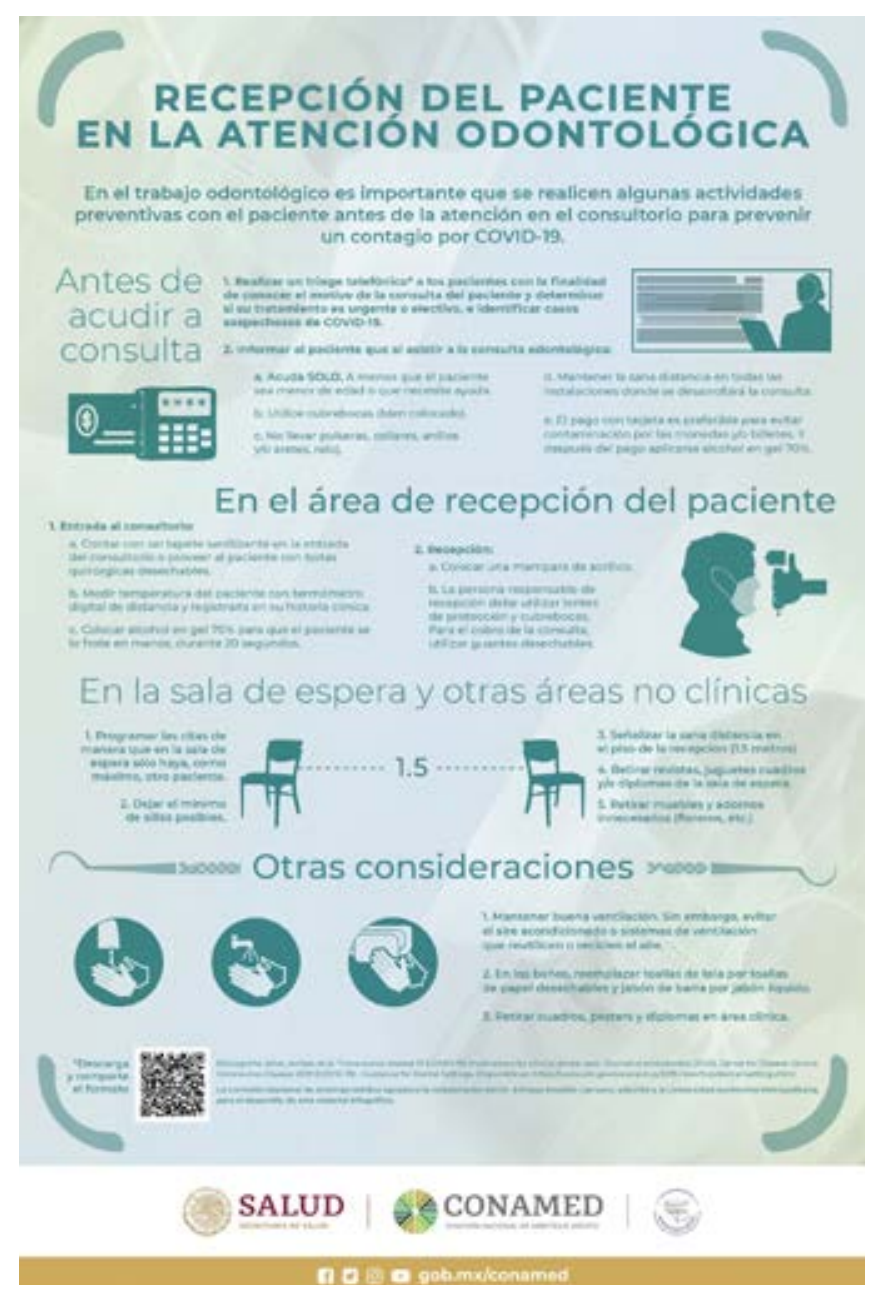

Figura 4: Infografía dirigida a odontólogos. CONAMED. México, 2020.

especialmente en el consultorio de primer contacto, la CONAMED desarrolló el webinar institucional «El COVID-19 y el consultorio médico» donde se transmitieron 19 sesiones en directo a través de Facebook Live. Los profesores participantes fueron, todos ellos, conocedores de la temática impartida y el impacto de COVID-19 (Tabla 3).

Los 19 webinar para Facebook Live tuvieron un alcance de 372,596 usuarios y 20,115 respuestas (interesados/asistentes) previas a la transmisión de cada evento, dando como resultado un total de 188,600 reproducciones promedio de cada conferencia. En total 948,948 personas vieron las 19 conferencias. Esto permitió a su vez acercar más a la institución con los profesionales de la salud del primer contacto, especialmente médicos, enfermeras y odontólogos (Figura 6).

\section{Campaña de comunicación social}

Se programó una campaña de comunicación social titulada «CONAMED Una instancia para la atención de quejas médicas 2020», cuyo objetivo fue promover a la CONAMED como la instancia donde la población general, incluida población hablante indígena, y profesionales de la salud pueden recibir apoyo en caso de un conflicto derivado de la atención a la salud. La campaña consistió en la difusión nacional por radio de 15 spots de 30 segundos de duración desde el 21 de noviembre hasta el 20 diciembre de 2020.

La difusión se realizó en dos etapas: la primera etapa consistió en la difusión del spot dirigido a población general (en español) y el mismo mensaje traducido a 13 lenguas indígenas (mam, mixteco, rarámuri, triqui, tzotzil, maya, mazahua, náhuatl, otomí, purépecha, tojolabal, tzeltal y zapoteco). La segunda etapa incluyó la difusión del spot (en español) dirigido a «profesionales de la salud». El total de impacto de transmisión de ambas etapas fue de 1,249 impactos en las estaciones de radio del Instituto Mexicano de la Radio (IMER). Los spots se distribuyeron a las comisiones estatales de arbitraje médico para su distribución local y están disponibles en la página web de la CONAMED.

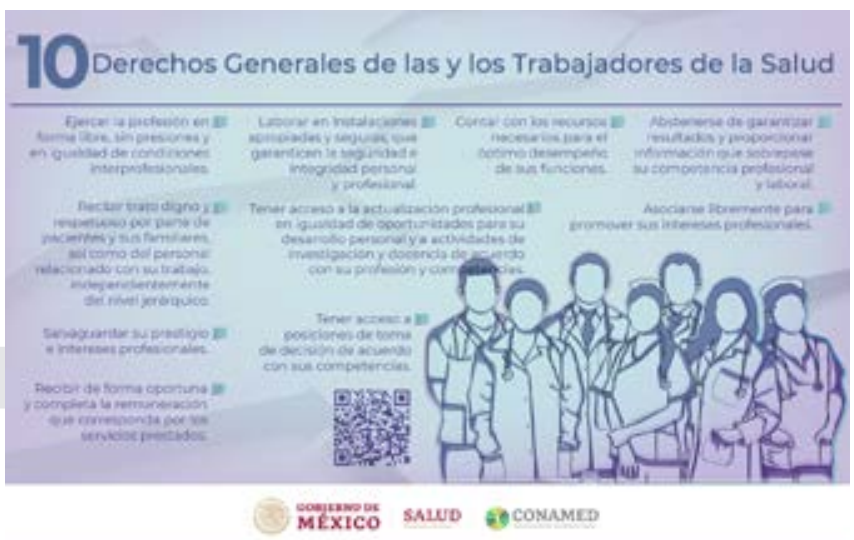

Figura 5: Ejemplo de uno de los 10 carteles distribuidos a las comisiones estatales de arbitraje médico e instituciones de salud. CONAMED. México, 2020. 
Tabla 3: Temas y conferencistas participantes en el webinar institucional «El COVID-19 y el consultorio médico». CONAMED, México. 2020.

\begin{tabular}{|c|c|c|c|}
\hline Ponente & Tema & Cargo & Institución \\
\hline Dr. José Jesús Ojino García & $\begin{array}{l}\text { Atención de pacientes } \\
\text { con COVID-19 en el } \\
\text { consultorio médico }\end{array}$ & $\begin{array}{l}\text { Director de Guías de } \\
\text { Prácticas Clínicas }\end{array}$ & $\begin{array}{l}\text { CENETEC/Secretaría } \\
\text { de Salud }\end{array}$ \\
\hline $\begin{array}{l}\text { Dr. Jesús Carlos } \\
\text { Briones Garduño }\end{array}$ & $\begin{array}{l}\text { COVID-19 y atención } \\
\text { de embarazadas en } \\
\text { el consultorio }\end{array}$ & $\begin{array}{l}\text { Director de medicina y } \\
\text { auxiliares diagnósticos }\end{array}$ & $\begin{array}{l}\text { Hospital General de México } \\
\text { «Dr. Eduardo Liceaga» }\end{array}$ \\
\hline $\begin{array}{l}\text { Dr. Francisco } \\
\text { Moreno Sánchez }\end{array}$ & $\begin{array}{l}\text { COVID-19, vacuna, y } \\
\text { el médico general }\end{array}$ & Infectólogo & Centro Médico ABC \\
\hline Dr. Juan José Sienra Monge & $\begin{array}{l}\text { COVID-19 y el paciente } \\
\text { asmático en el consultorio }\end{array}$ & $\begin{array}{l}\text { Subdirector de Pediatría } \\
\text { Ambulatoria }\end{array}$ & $\begin{array}{l}\text { Hospital Infantil de México } \\
\text { «Federico Gómez» }\end{array}$ \\
\hline Dr. José Moreno Rodríguez & $\begin{array}{l}\text { Las pruebas de detección } \\
\text { de COVID-19 y el consultorio } \\
\text { de medicina general }\end{array}$ & Director de Investigación & Hospital Juárez de México \\
\hline $\begin{array}{l}\text { Dr. José Alfonso } \\
\text { Maya Barrios }\end{array}$ & $\begin{array}{l}\text { COVID-19 y la atención } \\
\text { del niño en el consultorio } \\
\text { de medicina general }\end{array}$ & Pediatra & $\begin{array}{l}\text { Hospital General «Dr. } \\
\text { Manuel Gea González» }\end{array}$ \\
\hline $\begin{array}{l}\text { Dr. Heberto Arboleya/ } \\
\text { Dr. Rafael Valdez }\end{array}$ & $\begin{array}{l}\text { COVID-19 y la atención } \\
\text { hospitalaria... pero en casa }\end{array}$ & Director/Director Médico & $\begin{array}{l}\text { Unidad Temporal COVID-19 } \\
\text { Centro Banamex }\end{array}$ \\
\hline $\begin{array}{l}\text { Dra. Guadalupe Mercedes } \\
\text { Lucía Guerrero Avendaño }\end{array}$ & $\begin{array}{l}\text { El paciente con COVID-19 } \\
\text { y la lectura radiológica } \\
\text { en el consultorio }\end{array}$ & Directora general & $\begin{array}{l}\text { Hospital General de México } \\
\text { «Dr. Eduardo Liceaga» }\end{array}$ \\
\hline Dr. Niels Wacher Rodarte & $\begin{array}{l}\text { COVID-19 y diabetes } \\
\text { mellitus en el consultorio } \\
\text { de medicina general }\end{array}$ & $\begin{array}{l}\text { Jefe de la Unidad } \\
\text { de Investigación en } \\
\text { Epidemiología Clínica }\end{array}$ & $\begin{array}{l}\text { Hospital de Especialidades } \\
\text { «Dr. Bernardo Sepúlveda } \\
\text { Gutiérrez» del Centro } \\
\text { Médico Siglo XXI, IMSS }\end{array}$ \\
\hline $\begin{array}{l}\text { Dra. Jennifer } \\
\text { Hincapie Sánchez }\end{array}$ & $\begin{array}{l}\text { COVID-19 y la relación } \\
\text { médico paciente en } \\
\text { el consultorio }\end{array}$ & $\begin{array}{l}\text { Doctora en Filosofía. } \\
\text { Coordinadora del } \\
\text { Programa Institucional } \\
\text { de Ética y Bioética }\end{array}$ & $\begin{array}{l}\text { Facultad de Medicina } \\
\text { de la UNAM }\end{array}$ \\
\hline $\begin{array}{l}\text { Dr. Juan José Calva } \\
\text { Mercado }\end{array}$ & $\begin{array}{l}\text { COVID-19 y el paciente } \\
\text { con HIV en el consultorio } \\
\text { de medicina general }\end{array}$ & Medico Infectólogo & INNSZ \\
\hline $\begin{array}{l}\text { Dr. Enrique Ensaldo } \\
\text { Carrasco }\end{array}$ & $\begin{array}{l}\text { COVID-19 y el paciente } \\
\text { odontológico en el } \\
\text { consultorio odontológico }\end{array}$ & Profesor & UAM-Xochimilco \\
\hline $\begin{array}{l}\text { Mtra. Alma Lidia } \\
\text { Almiray Soto }\end{array}$ & $\begin{array}{l}\text { COVID-19 y la enfermera } \\
\text { en el consultorio } \\
\text { del primer nivel }\end{array}$ & Investigadora & $\begin{array}{l}\text { Unidad de Investigación } \\
\text { en Epidemiología Clínica } \\
\text { del Hospital Infantil de } \\
\text { México «Federico Gómez» }\end{array}$ \\
\hline Dra. Ana Berni Betancourt & $\begin{array}{l}\text { COVID-19 y el paciente } \\
\text { con hipertensión arterial } \\
\text { en el consultorio de } \\
\text { medicina general }\end{array}$ & Odontóloga. Tesorera & $\begin{array}{l}\text { Sociedad Mexicana } \\
\text { de Cardiología }\end{array}$ \\
\hline
\end{tabular}




\begin{tabular}{|c|c|c|c|}
\hline \multicolumn{4}{|c|}{$\begin{array}{l}\text { Continúa la Tabla 3: Temas y conferencistas participantes en el webinar institucional } \\
\text { «EI COVID-19 y el consultorio médico». CONAMED, México. } 2020 .\end{array}$} \\
\hline Ponente & Tema & Cargo & Institución \\
\hline $\begin{array}{l}\text { Dr. Alejandro Macías } \\
\text { Hernández }\end{array}$ & $\begin{array}{l}\text { La interacción de COVID-19 } \\
\text { e influenza. El manejo } \\
\text { por el médico general }\end{array}$ & $\begin{array}{l}\text { Médico Especialista } \\
\text { en Medicina Interna } \\
\text { e Infectología }\end{array}$ & $\begin{array}{l}\text { Departamento de Medicina } \\
\text { y Nutrición. Universidad } \\
\text { de Guanajuato }\end{array}$ \\
\hline $\begin{array}{l}\text { Dr. Luis Miguel } \\
\text { Gutiérrez Robledo }\end{array}$ & $\begin{array}{l}\text { COVID-19 y el paciente } \\
\text { geriátrico en el consultorio } \\
\text { del primer nivel }\end{array}$ & Director General & $\begin{array}{l}\text { Instituto Nacional } \\
\text { de Geriatría }\end{array}$ \\
\hline $\begin{array}{l}\text { Dra. Liliana Sánchez } \\
\text { González }\end{array}$ & $\begin{array}{l}\text { COVID-19 y dengue } \\
\text { en el consultorio de } \\
\text { medicina general }\end{array}$ & Epidemióloga & $\begin{array}{l}\text { Dengue Branch-Division } \\
\text { of Vector Borne Diseases. } \\
\text { Centers for Disease } \\
\text { Control and Prevention }\end{array}$ \\
\hline Dra. Claudia Marcela Vélez & $\begin{array}{l}\text { Situación actual sobre las } \\
\text { vacunas disponibles para } \\
\text { COVID-19 y el consultorio } \\
\text { de medicina general }\end{array}$ & Profesora e Investigadora & $\begin{array}{l}\text { Facultad de Medicina } \\
\text { de la Universidad de } \\
\text { Antioquia, Colombia }\end{array}$ \\
\hline Dr. José Halabe & $\begin{array}{l}\text { Síndrome post-COVID en el } \\
\text { consultorio del primer nivel }\end{array}$ & & $\begin{array}{l}\text { Facultad de Medicina } \\
\text { de la UNAM/Academia } \\
\text { Nacional de Medicina }\end{array}$ \\
\hline
\end{tabular}

http://www.conamed.gob.mx/gobmx/estamos_para_ayudarte/poblaciongeneral.php

\section{Programa de investigación}

Aun con las restricciones establecidas por la pandemia para el desarrollo de las actividades, las comisiones de investigación y de bioética para la investigación continuaron sesionando de forma virtual. Por otro lado, los proyectos de investigación continuaron su marcha. Destaca un proyecto en especial que se inició en 2019 en las personas servidoras públicas de la CONAMED denominado «Estrés laboral y síndrome de quemarse por el trabajo en la Comisión Nacional de Arbitraje Médico», que consistió básicamente en realizar un diagnóstico sobre la salud mental negativa (estrés laboral y síndrome de quemarse por el trabajo) y positiva (entusiasmo laboral) en personal de la comisión. En 2019 se realizó la primera evaluación y en 2020 se requería realizar una segunda evaluación. Aún con las condiciones laborales establecidas por la pandemia, ese segundo levantamiento se realizó en la última semana de octubre de 2020 con una buena participación (72 trabajadores) y los

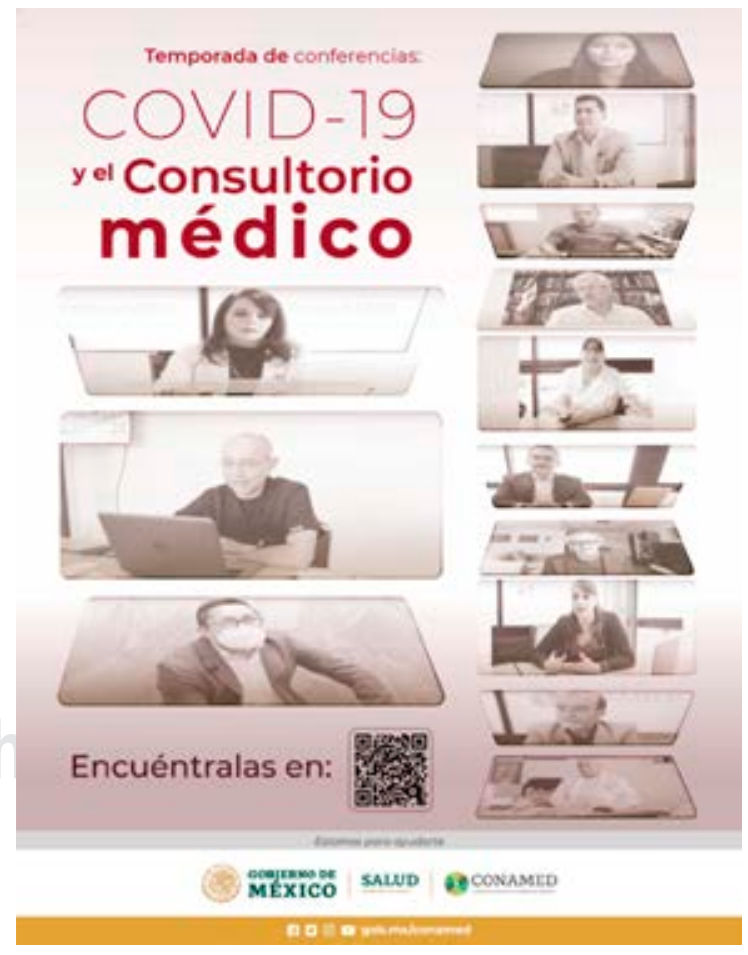

Figura 6: Infografía utilizada para la difusión del webinar institucional "El COVID-19 y el consultorio médico». CONAMED, México. 2020. 


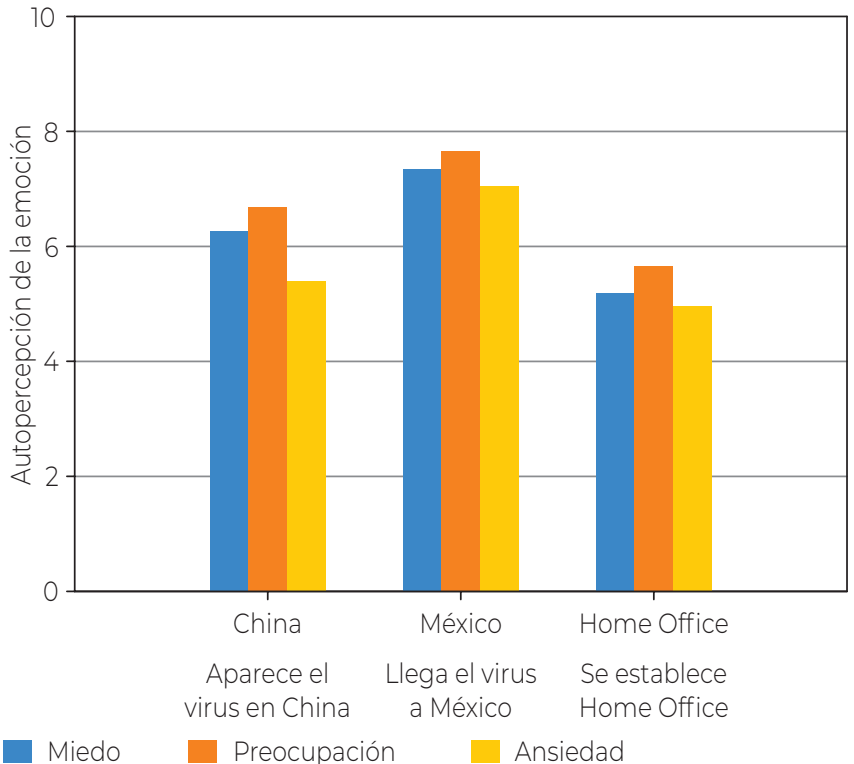

Figura 7: Comparación de la autopercepción de emociones adversas relacionadas con la pandemia COVID-19. Estudio «Estrés laboral y síndrome de quemarse por el trabajo en la Comisión Nacional de Arbitraje Médico» 2020. CONAMED. México.

resultados mostraron que la llegada de la COVID-19 a México disparó la autopercepción de emociones adversas. El establecimiento del «home office» las redujo a niveles autopercibidos previos a la llegada del COVID-19, como un efecto de seguridad personal (Figura 7).

\section{Reunión con las comisiones estatales de Arbitraje Médico}

Las condiciones de confinamiento de la pandemia no fue obstáculo para que el 4 de diciembre de 2020 se realizará la trigésima sexta sesión ordinaria del Consejo Mexicano de Arbitraje Médico con la participación de los titulares de las 28 comisiones estatales integrantes del Consejo. Lo novedoso de esta reunión fue que se realizó por videoconferencia. Aquí tratamos temas de interés para las comisiones estatales, en su mayoría relacionadas con la pandemia causada por el coronavirus SARS-CoV-2.

\section{El regreso a las actividades in situ}

En mayo de 2021 se tomó la decisión de regresar a lasactividades en oficina manteniendo las medidas

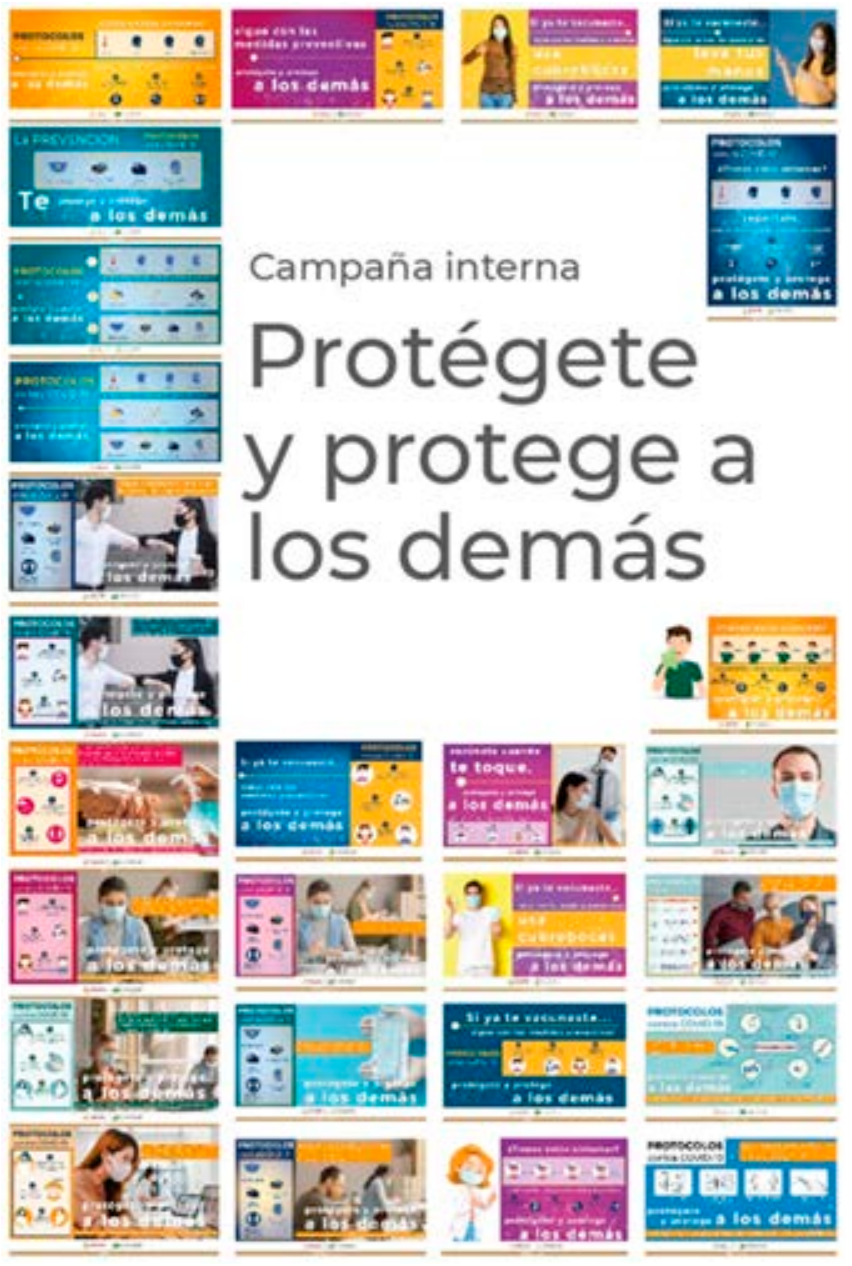

Figura 8: Infografías distribuidas al interior de la institución para fortalecer el mensaje de prevención y de la vacunación contra COVID-19. CONAMED. México, 2021.

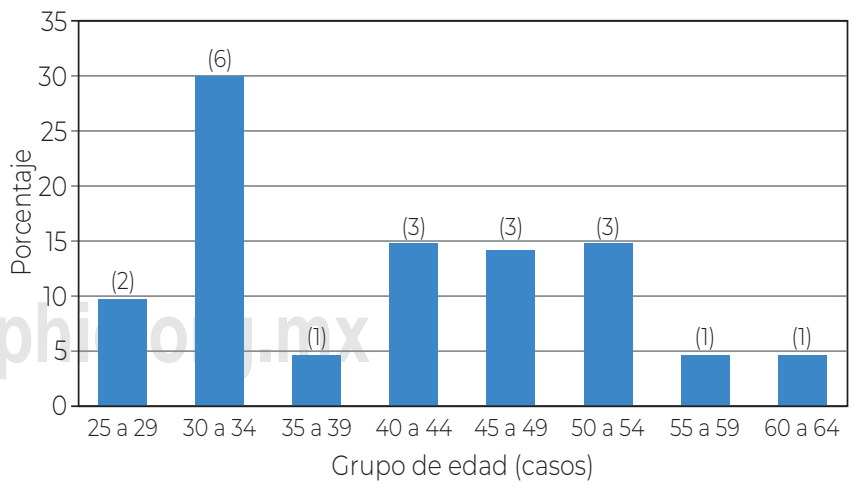

Dirección de Administración. CONAMED, 2027

Figura 9: Distribución porcentual de casos positivos a COVID-19 según edad en personal de la CONAMED. México, 2020-2021. $\mathrm{N}=20$. 
de prevención para reducir el contagio por COVID-19 y se implantó una campaña de prevención dirigida a los trabajadores de la CONAMED (protégete contra el COVID-19 y protege a los demás) con mensajes orientados a continuar con el protocolo de medidas de prevención, así como la necesidad de vacunarse, informar de las fechas de aplicación de las dosis y, en caso que así pasara, informar si alguno de ellos presentaba síntomas compatibles con la infección para enviar al trabajador a realizarse la prueba diagnóstica y en caso de ser positivo, enviarlo a su casa con las recomendaciones para el cuidado personal y familiar. En la Figura 8 se muestran

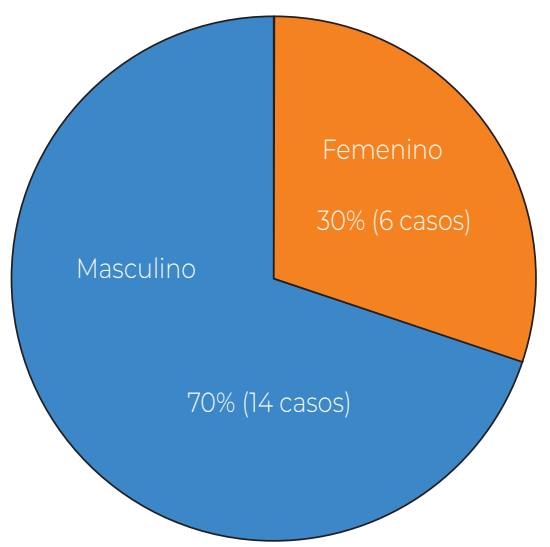

Dirección de Administración. CONAMED, 2021

Figura 10: Distribución porcentual de casos positivos a COVID-19 según sexo en personal de la CONAMED. México, 2020-2021. algunas de las infografías distribuidas al interior de la institución.

\section{Los trabajadores contagiados}

La CONAMED no estuvo excluida de la transmisión del virus SARS-CoV-2 en la salud de sus trabajadores. Se instaló un sistema de comunicación para que aquellas personas servidoras públicas que presentaran síntomas relacionados con COVID-19 informaran inmediatamente para dar seguimiento a los contactos dentro de la institución. En 2020 solamente se reportaron dos casos positivos confirmados con PCR (tasa ataque institucional $=1.7 \%$ ), y entre enero y octubre de 2021 se reportaron 18 casos positivos confirmados adicionales (tasa ataque institucional $=15.4 \%$ ).

La mayor proporción de los casos fue en el grupo de edad de 30 a 34 años (30\%) (Figura 9), y en la distribución por sexo los hombres fueron los más afectados (70\%) (Figura 10).

De los 18 casos registrados en 2021, 10 (55.6\%) se registraron después del regreso a la actividad presencial completa, por ello se instrumentó la campaña interna de prevención «Protégete del COVID-19 y protege a los demás» (Figura 77).

\section{Vacunación del personal}

Cuando se dio a conocer la Política Nacional de Vacunación contra el virus SARS-CoV-2, para la prevención de la COVID-19 en México, ${ }^{5}$ se inició un proceso de concientización en el personal de la CONAMED a fin

Figura 11:

Distribución de casos positivos a COVID-19 en personal de la CONAMED según fecha de presentación. México, 2020-2021.

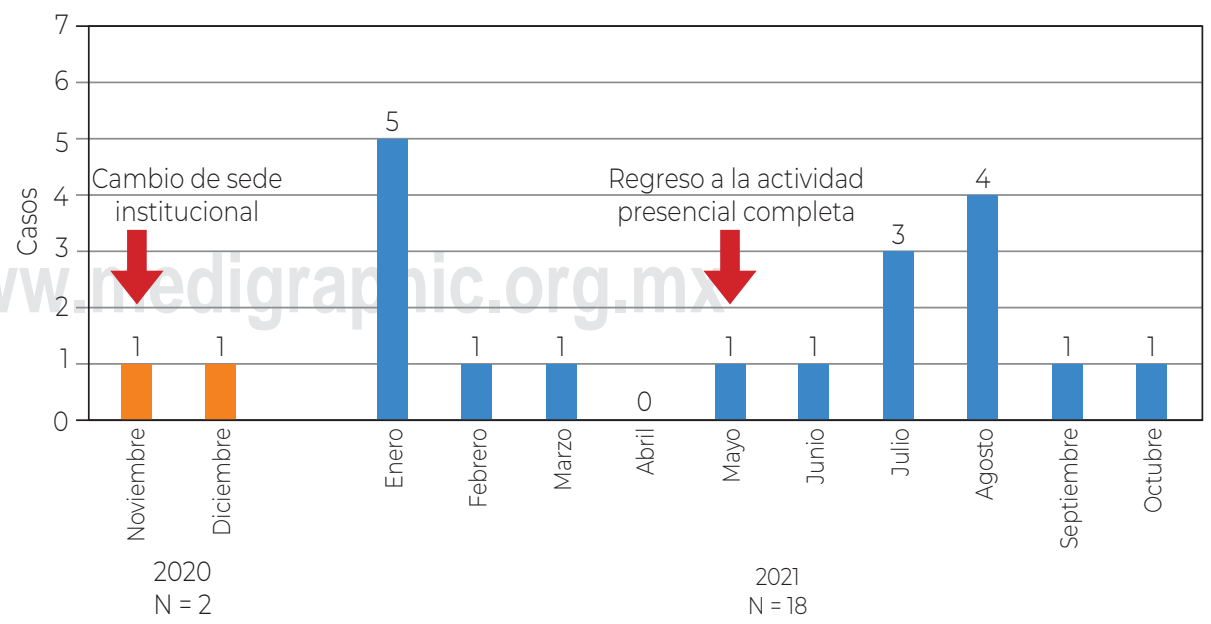




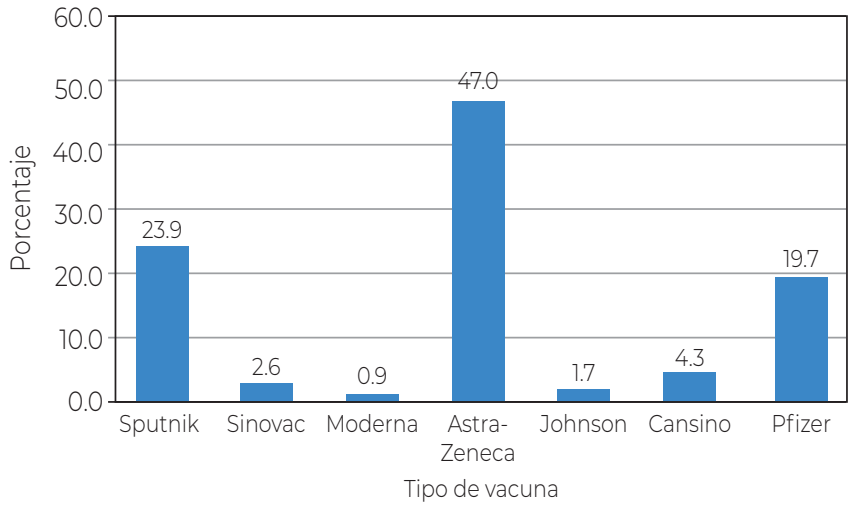

Dirección de Administración. CONAMED

Figura 12: Distribución porcentual del tipo de vacuna contra COVID-19 recibida por el personal de la CONAMED. México, 2021.

de que acudieran a recibir la primera y segunda dosis de la vacuna, de acuerdo con las fechas establecidas por las autoridades de salud. La respuesta del personal fue muy buena, ya que de una plantilla de 117 trabajadores, al momento de este reporte se ha vacunado con esquema completo 100\% de los mismos. El personal recibió siete diferentes tipos de vacunas, pero la predominante fue AstraZeneca (47.0\%) (Figura 12).

Del personal vacunado, 55.5\% fueron mujeres y los grupos de edad donde predominó la vacunación fueron los de 30 a 54 años.

La vacuna AstraZeneca predominó en los grupos de edad de 35 a 49 años, en comparación con la vacuna Sputnik V que tuvo una mayor presencia en los menores de 40 años. Hay que recordar que esta distribución refleja el efecto combinado del grupo de edad y del domicilio de cada uno de los vacunados (Figura 13).

\section{EPÍLOGO}

Durante 2021 la Comisión ha seguido trabajando en las oficinas teniendo como herramienta útil las videoconferencias. La comunicación virtual con el uso de diversas plataformas permitió conocer el potencial de desarrollo y continuidad de las actividades en situaciones de emergencia; en la CONAMED aprovechamos la disponibilidad de dichas plataformas y hoy continúan siendo una herramienta de gran utilidad para la comunicación dentro de la institución, con nuestros pares y con el público en general.

El proyecto sobre estrés nos mostró una realidad entre los trabajadores, esto es, una buena cantidad de ellos se encontraba bajo un proceso de presión tanto por la nueva dinámica de trabajo como por la pandemia por COVID-19 y los riesgos que ella implicaba para su salud y la de sus familias.

Con base en esos resultados establecimos una colaboración con el Instituto Nacional de Psiquiatría Juan Ramón de la Fuente Muñiz, se organizó una intervención psicoeducativa para los trabajadores

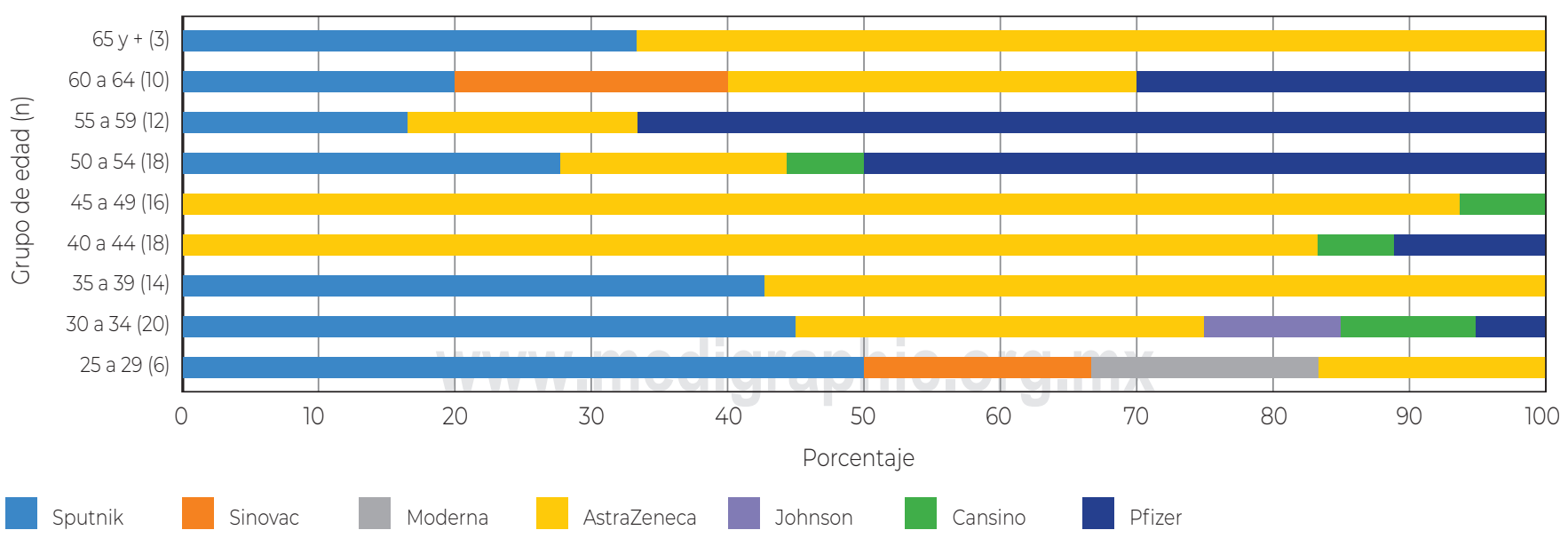

Fuente: Dirección de Administración. CONAMED

Figura 13: Distribución porcentual de vacunados contra COVID-19 según grupo de edad y marca de la vacuna recibida por el personal de la CONAMED. México, 2021. 


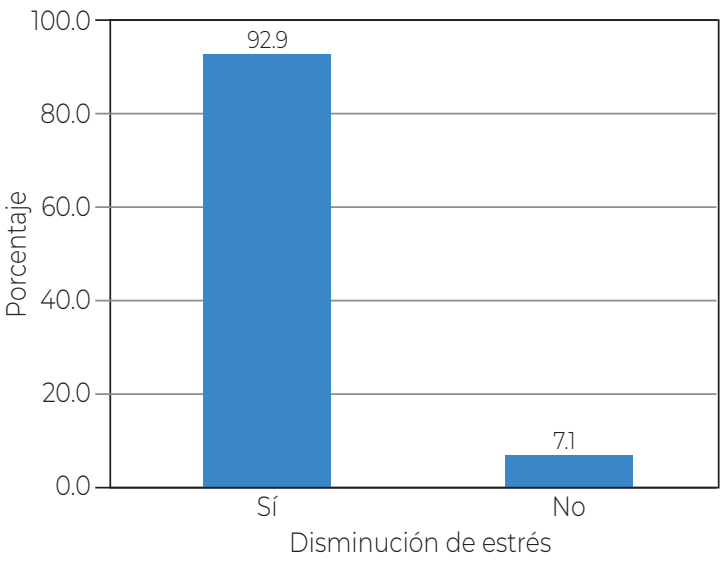

Figura 14: Distribución porcentual de la disminución del grado de estrés reportado por los participantes del taller «Técnicas de afrontamiento de estrés laboral» CONAMED. México, 2021.

de la CONAMED con un taller denominado «Técnicas de afrontamiento de estrés laboral» que tuvo una duración de 8 horas y se impartió del 20 de julio al 10 de septiembre de 2021. Se inscribieron 90 trabajadores y 79 (87.8\%) recibieron constancia de asistencia. El beneficio de este taller en los trabajadores se refleja en la disminución de hasta $53.1 \%$ en los niveles percibidos de estrés reportada por más de $90 \%$ de ellos (Figura 74).

Por otro lado, hay que resaltar que en el mes de junio de 2021 se cumplieron 25 años de la creación por Decreto Presidencial de la CONAMED, para celebrar este aniversario se organizó un seminario académico que se transmitió en línea que, además de ampliamente difundido, tuvo una concurrencia importante.

Aún seguimos en fase pandémica por la $\mathrm{CO}$ VID-19 y una de las lecciones aprendidas es que la CONAMED, tras 25 años de existencia, tiene la capacidad para responder a la sociedad y seguir cumpliendo su misión en situaciones «normales» y durante una emergencia en salud pública.

Estamos seguros que ante la «normalidad diferente» que se ha generado a partir de la pandemia, la CONAMED estará presente con la población y con los profesionales de la salud.

\section{AGRADECIMIENTOS}

Todos los resultados de las actividades de la CONAMED no hubieran sido posible sin la participación, empeño, disposición, capacidades y destrezas de las personas servidoras públicas de la Comisión Nacional de Arbitraje Médico, vaya el reconocimiento para todas ellas por seguir engrandeciendo nuestra institución.

\section{REFERENCIAS}

1. Pan American Health Organization/World Health Organization. COVID-19. Washington, D.C.: PAHO/ WHO; 2020. Available in: https://iris.paho.org/ bitstream/handle/10665.2/52403/COVID-19SitRepl_eng. pdf? sequence=7\&isAllowed=y

2. Secretaría de Salud. Dirección General de Epidemiología. Aviso epidemiológico. CONAVE /08/2020/COVID-19. Enfermedad COVID-19 por SARS-CoV-2. 17 de marzo de 2020. [Consultado el 6 de octubre de 2021] Disponible en: https://www.gob.mx/salud/documentos/avisoepidemiologico-enfermedad-covid-19-por-sars-cov-2

3. Diario Oficial de la Federación. Acuerdo por el que se establecen los criterios en materia de administración de recursos humanos para contener la propagación del coronavirus COVID-19, en las dependenciasy entidades de la Administración Pública Federal. México: 2020. [Consultado el 8 de octubre de 2021] Disponible en: https://dof.gob.mx/ nota_detalle.php?codigo=5590157\&fecha=23/03/2020

4. Diario Oficial de la Federación. ACUERDO por el que se establecen las medidas preventivas que se deberán implementar para la mitigación y control de los riesgos para la salud que implica la enfermedad por el virus SARSCoV-2 (COVID-19). México: 24 marzo 2020. [Consultado el 8 de octubre de 2021] Disponible en: https://www.dof.gob. mx/nota_detalle.php?codigo=5590339\&fecha $=24 / 03 / 2020$

5. Secretaría de Salud. Política Nacional de Vacunación contra el virus SARS-CoV-2, para la prevención de la COVID-19 en México. Documento Rector. V 4.0.11 de enero de 2021. [Consultado el 8 de octubre de 2021] Disponible en: https://coronavirus.gob.mx/wp-content/uploads/2027/07/ PolVx_COVID_-11Ene2021.pdf 